\title{
Role of the sympathetic nervous system in chronic joint pain and inflammation
}

\author{
B L Kidd, S Cruwys, P I Mapp, D R Blake
}

A substantial body of evidence gathered from a variety of diseases points to a critical interaction between the sympathetic nervous system and the inflammatory cascade. An important sympathetic component to rheumatic disease is indicated by the observation that symptoms in both reflex sympathetic dystrophy and rheumatoid arthritis may be alleviated after regional sympathectomy. ${ }^{1-3}$

Clearly, attempts to explain pathophysiological mechanisms must take observations such as these into account. This review summarises the evidence for a sympathetic influence on rheumatic disease and speculates on the mechanism by which this may arise.

\section{Clinical observations}

In 1864 Mitchell, Morehouse, and Keen reported the case of a soldier in the American Civil War who sustained a gunshot wound to the left upper arm. The second day after the injury the soldier developed excruciating pain in the arm such that light touch or even heavy steps in the room caused unbearable discomfort. ${ }^{4}$ This unfortunate state continued for months after the original wound had healed and was termed 'causalgia' by Mitchell and colleagues. ${ }^{4}$

Since then a number of other terms have been used to describe disorders characterised by persistent pain, vasomotor disturbance, and trophic change. These include Sudeck's atrophy, shoulder-hand syndrome, algodystrophy, and reflex sympathetic dystrophy. ${ }^{5}$ Pathological mechanisms have yet to be clearly established, but three important clinical observations suggest that the sympathetic nervous system plays a part. ${ }^{6}$ As observed by Mitchell, pain in these disorders is exacerbated by stimuli that evoke sympathetic discharge, such as noise and emotional arousal. Secondly, the disorders are associated with vasomotor and sweating disturbances, suggestive of abnormal sympathetic activity. Finally, patients with these disorders often have a dramatic and prolonged response to guanethidine, reserpine, and other agents which alter sympathetic activity. ${ }^{15}$

Sympathectomy has also been used to treat rheumatoid arthritis. ${ }^{2}{ }^{7}$ In 1927 Rowntree and Adson described a series of young patients with rheumatoid arthritis whose symptoms improved after sympathetic ganglionectomy. ${ }^{7}$ Flothow in 1930, Leriche and Jung in 1933, and Young in 1936 all reported relief of articular pain in small series of patients with rheumatoid arthritis. ${ }^{7}$ A later study by Hertford of patients with intractable hip or knee pain reported that six of seven patients received substantial symptomatic relief after lumbar sympathectomy. Several of the patients had reduction of joint swelling and improvement of cutaneous ulcers in the sympathectomised limb. The relief of symptoms was observed for follow up periods lasting from four to 24 months. ${ }^{7}$

More recently, Levine and colleagues investigated the effects of regional sympathetic blockade using guanethidine in 24 patients with active rheumatoid arthritis. ${ }^{3}$ In a randomised, double blind study guanethidine was found to decrease pain and increase pinch strength over the two week duration of the study. No significant improvement was noted in grip strength, joint tenderness, or duration of morning stiffness.

\section{Reflex sympathetic dystrophy}

Persistent pain, often described as having a burning quality, is the hallmark of this disorder. ${ }^{58}$ Vasomotor disturbances are common and include vasodilatation with warm erythematous skin, vasoconstriction with cool pallid skin, occasional Raynaud's phenomenon, and excessive sweating. ${ }^{8}$ Months or years after onset of symptoms subcutaneous atrophy and irreversible flexion contractures may develop with a resultant pale, cold, and painful extremity. ${ }^{5}$

Patchy osteoporosis may be present early in the course of the disease, progressing to more diffuse change later. ${ }^{8}$ Kozin and colleagues reported a high incidence of bilateral involvement with the articular areas being the most affected. 9 Synovial biopsy specimens show varying degrees of oedema, increased vascularity, and proliferation of synovial lining cells, an appearance similar to that found in frozen shoulder. ${ }^{9}$

The pathogenesis of reflex sympathetic dystrophy remains unclear, but, multiple factors are probably involved both centrally and peripherally. In 1943 Livingstone proposed that chronic stimulation of afferent fibres, which respond to noxious stimuli (nociceptors), produced excessive excitation in spinal internuncial neurones causing abnormal sympathetic efferent activity. ${ }^{10}$ Subsequently, Roberts speculated that maintenance of the disorder depends not so much on persistent nociceptor irritation but rather on abnormal central processing of apparently normal mechanoceptor input into the spinal cord. ${ }^{11}$

A number of investigators have focused on peripheral mechanisms. ${ }^{12-15}$ It is known that iontophoretic application of noradrenaline is an 
effective pain stimulus in patients with reflex sympathetic dystrophy ${ }^{13}$ and that sympathetic blockade may result in symptomatic relief whether or not the block is performed centrally or peripherally. ${ }^{14}$ In contrast, catecholamines do not cause pain in normal subjects and sympathetic blockade does not impair pain sensation. ${ }^{12}$ These observations support the proposal by Janig that a vicious circle of excitation of primary afferent fibres by postganglionic sympathetic fibres maintains the pathophysiological process in this disorder. ${ }^{15}$

The best experimental evidence for peripheral interactions between afferent and sympathetic fibres comes from observations made of neuronal activity in stump neuromas. ${ }^{16}$ In this experimental model transection and ligation of a major nerve are followed by development of a stump neuroma. Subsequently, damaged afferent fibres sprout within the neuroma and, unlike undamaged afferent fibres, respond to sympathetic stimulation and the application of catecholamines. ${ }^{17}$ More recent models which retain some nerve contact with the target tissue using subtotal resection or ligature constriction have shown a similar result. ${ }^{18}$

Present evidence supports a role for the sympathetic nervous system in the development and maintenance of reflex sympathetic dystrophy. Preceding nerve or tissue trauma can be demonstrated in over half the patients presenting with this disorder. ${ }^{8}$ It seems likely that in this situation continuing stimulation of damaged afferent fibres by sympathetic activity is at least partially responsible for the chronic pain state observed clinically. ${ }^{12}$

\section{Experimental arthritis}

On a more general level a number of experimental studies have examined the contribution of neural components to the expression and outcome of arthritis. The earliest, by Courtright and Kuzell in 1965, suggested that prior section of a sciatic nerve delayed the onset and diminished the extent of rat adjuvant arthritis in the operated limb when compared with the opposite side. ${ }^{19}$ These results contrast markedly with a later study by Rees $e t a l$, which reported that sciatic nerve section substantially exacerbated disease as judged on clinical and radiological grounds. ${ }^{20}$

There is accord, however, between studies by Rees $e t a l$ and Levine $e t a l$, which both show an attenuation of adjuvant disease after sympathectomy or selective destruction of small diameter sensory nerves. ${ }^{20} 21$ These studies also show a significant exacerbation of disease following posterior nerve root section. Both Rees et al and Levine et al stress the importance of an intact sympathetic nerve supply on the severity of arthritis and, interestingly, Levine has shown that the enhanced disease seen in the rhizotomised limbs may be markedly reduced by prior sympathectomy. The importance of sympathetic activity is further shown by the observation that in spontaneously hypertensive rats, which have increased sympathetic tone, adjuvant arthritis is more severe than in normotensive control animals. ${ }^{21}$
A series of studies by Levine and colleagues examined the relation between sympathetic postganglionic nerve terminals and severity of experimental arthritis. ${ }^{22-24}$ Their early studies indicated that blockade of the $\mathrm{B} 2$ receptor on the sympathetic postganglionic nerve terminal significantly attenuated adjuvant arthritis and that the effect was independent of the timing of inhibition relative to the onset of clinical disease. ${ }^{22} \mathrm{~A}$ similar attenuation was seen after adrenal medullectomy, reversible by administration of adrenaline but only in the presence of an intact sympathetic nervous system, suggesting mediation via the sympathetic postganglionic nerve terminal. ${ }^{23}$ From these studies Levine suggested that catecholamines acting on sympathetic postganglionic nerve terminals induce the release of unknown compounds responsible for the deleterious effects of sympathetic activity on adjuvant disease. ${ }^{24}$

The clear influence of the sympathetic nervous system on experimental arthritis, coupled with the failure of adrenergic mediators to influence the outcome directly, suggests that non-adrenergic mechanisms may be involved. Postganglionic sympathetic nerves can be divided into two broad groups: those innervating sweat glands and skeletal muscle blood vessels containing acetylcholine, and the vast majority of fibres containing noradrenaline. A subgroup of the latter fibres also contains other neurotransmitters, including neuropeptide $Y$, adenosine triphosphate, and nitric oxide. ${ }^{25}$ The role of these agents in both normal and abnormal situations is currently the subject of intensive speculation and investigation.

Neuropeptide $\mathrm{Y}$ is a 36 amino acid peptide with a number of diverse physiological effects, including vasoconstriction and potentiation of the actions of other neurotransmitters such as noradrenaline. ${ }^{26}$ It also acts presynaptically to inhibit its own release and that of noradrenaline and 5-hydroxytryptamine. In high doses neuropeptide $\mathrm{Y}$ induces histamine release from mast cells, and in vitro studies suggest that it has a role in regulating osteoblast function. ${ }^{27}$ Agonist studies indicate that there are at least three subtypes of neuropeptide $\mathrm{Y}$ receptor and, recently, a number of receptor antagonists have been described. ${ }^{28}$

Edvinsson and colleagues have recently introduced an inositol derivative, D-myo-inositol1,2,6-trisphosphate (PP56), as a functional antagonist of vasoconstriction induced by neuropeptide Y. ${ }^{29}$ Significantly, PP56 has been shown to exert anti-inflammatory effects in several experimental models of arthritis, including reduction of oedema in both acute carrageenin induced inflammation and chronic adjuvant arthritis. ${ }^{30}$

\section{Rheumatoid arthritis}

Sympathetic overactivity in reflex sympathetic dystrophy is associated with pain and juxtaarticular disease, including synovitis, and there appear to be important sympathetic influences on the outcome of experimental adjuvant arthritis. How then might these observations reflect pathogenic mechanisms in rheumatoid arthritis? 
Clearly, normal human synovium is richly innervated with both sympathetic and afferent nerve fibres. ${ }^{31}$ Immunocytochemical studies using antisera against protein gene product 9.5 (PGP 9.5) as a marker for the overall innervation have shown fibres distributed around blood vessels and lying freely within synovium. Nearly all these nerves are immunoreactive for neuropeptides with neuropeptide $\mathrm{Y}$ immunoreactive fibres being exclusively located around blood vessels, whereas substance $P$ and calcitonin gene related peptide immunoreactive fibres are located in both free and perivascular areas. ${ }^{31}$ The exact function of these peptides remains uncertain, but in addition to vascular regulation they probably play a part in immunoregulation and bone metabolism. ${ }^{32}$

In rheumatoid arthritis the more superficial synovial tissues, including blood vessels and the intimal cell layer, are devoid of fibres immunoreactive for PGP 9.5 or any of the individual neuropeptides. ${ }^{33}$ In deeper tissues the innervation is similar to normal tissues, but the immunostaining is weaker and fibres take on a beaded appearance with small lengths appearing unstained. A similar loss of immunoreactive fibres has also been seen in experimental models, including adjuvant arthritis. ${ }^{34}$

The absence of immunoreactive fibres in the superficial layers of rheumatoid synovium might suggest that there is an increased release of substance $P$, calcitonin gene related peptide, and neuropeptide $Y$, which thereby reduces the neuronal stores to levels below that detectable by immunocytochemistry. As the immunostaining for the neuronal marker PGP 9.5 is also lost, however, it seems more probable that nerve fibres in the superficial layers are destroyed. ${ }^{33}$

The loss of synovial nerves in rheumatoid arthritis is potentially caused by products of the inflammatory cascade. In studies using hypoxanthine/xanthine oxidase as a means of generating reactive oxygen species it is apparent that neuropeptides are vulnerable to damage. ${ }^{35}$ Our own unpublished študies have shown rapid loss of synovial nerve fibres in a glucose oxidase model of inflammation which is known to depend on production of hydrogen peroxide. Exercised rheumatoid joints are subjected to 'intermittent' episodes of hypoxia, thus creating the conditions necessary for hypoxic-reperfusion events and the subsequent production of similarly destructive reactive oxygen species. ${ }^{36}$

We speculate that a direct consequence of nerve damage in diseased joints is that synovial afferent fibres become sensitised to continuing sympathetic activity. This is supported by the observations made of the stump neuroma where damaged afferents respond to sympathetic stimulation and application of catecholamines. Within the heavily innervated human joint persistent afferent stimulation would inevitably lead to chronic pain. The situation would be compounded by the hypoxic nature of inflamed joints ${ }^{37}$ as hypoxia induces both enhanced responsiveness to sympathetic stimulation and reversible increases in the number of receptors on sympathetic postganglionic nerve terminals. $^{38}$
Persistent sympathetic stimulation of afferent nerves in rheumatoid synovium implies that activation of afferents responding to noxious stimuli would no longer depend critically on prostaglandins and other hyperalgesic products of inflammation. This is borne out clinically as there is poor correlation between pain and clinical and laboratory indices of inflammation, ${ }^{39}$ and basic clinical observation indicates that conventional anti-inflammatory drugs do not provide satisfactory analgesia in all patients. Sympathetic stimulation of nociceptors would also explain the beneficial effects of sympathectomy described earlier.

It is apparent that sympathetic mechanisms may have an important role in joint inflammation. Existing treatment with adrenoceptor antagonists only partially inhibits sympathetic transmission within the joint, leaving nonadrenergic function intact. The increasing availability of adrenergic and non-adrenergic inhibitors therefore offers intriguing potential for further exploration and eventual therapeutic use.

The authors would like to acknowledge the financial support of the Arthritis and Rheumatism Council.

1 Hannington-Kiff J G. Relief of Sudeck's atrophy by regional intravenous guanethidine. Lancet 1977; i: 1132-3.

2 Hannington-Kiff J G. Rheumatoid arthritis-interventional treatment with regionally applied drugs and the use of sympathetic modulation: discussion paper. $\mathcal{J} R$ Soc Med 1990: 83: 373-6.

3 Levine J D, Fye K, Heller P, Basbaum Al, Whiting-O'Keefe $Q$. Clinical response to regional intravenous guanethidine in patients with rheumatoid arthritis. F Rheumatol 1986; 13 1040-3.

4 Mitchell S W, Morehouse G R, Keen W W. Gunshot wounds and other injuries of nerves, Philadelphia: Lippincott, 1864.

5 Swartzman R J, McLellan T L. Reflex sympathetic dystrophy. A review. Arch Neurol 1987; 44: 555-61.

6 Bennet G J. The role of the sympathetic nervous system in painful peripheral neuropathy. Pain 1191; 45: 221-3.

7 Hertford R A. Extended sympathectomy in the treatment of chronic rheumatoid arthritis. F Am Geriat Soc 1957; 5: 904-15.

8 Chard M D. Diagnosis and management of algodystrophy. Ann Rheum Dis 1991; 50: 727-30.

9 Kozin F, McCarty D J, Sims J, Genant H. The reflex sympathetic dystrophy syndrome. 1 . Clinical and histologic sympathetic dystrophy syndrome. l. Clinical and histologic studies: evidence for bilaterality, response to corticosteroids
and articular involvement. Am $\mathcal{f}$ Med 1976; 60: 32l-31.

10 Livingstone W K. Pain mechanisms: a physiologic interpretation of causalgia and its related states. New York: Macmillan 1943.

11 Roberts W. A hypothesis on the physiological basis for causalgia and related pains. Pain 1986; 24: 297-311.

12 Koltzenburg M, McMahon S B. The enigmatic role of the sympathetic nervous system in chronic pain. Trends Pharmacol Sci 1991; 12: 399-402.

13 Wallin G, Torebiork E, Hallin R. Preliminary observations on the pathophysiology of hyperalgesia in the causalgic pain on the pathophysiology or $\mathrm{Y}$, ctions of the skin in primates: with special reference to man. Vol 27. (WennerGren Center International Symposium Series.) Oxford: Pergamon Press, 1976: 489-502.

14 Bonelli S, Conoscente F, Movilia P G, et al. Regiona intravenous guanethidine vs stellate ganglion block in reflex sympathetic dystrophies: a randomised trial. Pain 1983; 16 297-307

15 Janig $\mathrm{W}$. The sympathetic nervous system in pain: physiology and pathophysiology. In: Stanton-Hicks M, ed. Pain and the sympathetic nervous system. Boston and London Kluwer Academic, 17-89.

16 Wall $P$ D, Gutnick M. Ongoing activity in peripheral nerves: the physiology and pharmacology of impulses originating from a neuroma. Exp Neurol 1974; 43: 580-93.

17 Devor $M$. Nerve pathophysiology and mechanisms of pain in causalgia. F Auton Nerv Syst 1983; 7: 371-84

18 Seltzer Z, Dubner R, Shir Y. A novel behavioural model of neuropathic pain disorders produced in rats by partial sciatic nerve section. Pain 1990; 43: 205-18.

19 Courtright L J, Kuzell W C. Sparing effects of neurological deficit and trauma on the course of adjuvant arthritis in rats. deficit and trauma on the course

20 Rees R G, Dixey J J, Lightman S L, et al. Selective neura manipulation can profoundly alter the course of adjuvant manipulation can profoundly alter the course of adjuva

21 Levine J D, Dardick S J, Roizen M F, Helms C. Contribution of sensory afferents and sympathetic efferents to 
joint injury in experimental arthritis. 7 Neurosci 1986; 6 : 3423-9.

22 Levine J D, Coderre T J, Helms C, et al. $\beta_{2}$-Adrenergic mechanisms in experimental arthritis. Proc Natl Acad Sci USA 1988; 85: 4553-6.

23 Coderre T J, Basbaum Al, Dallman M F, et al. Epinephrine exacerbates arthritus by an action at presynaptic B2-adrenoceptors. Neuroscience 1990; 34: 521-3.

24 Coderre T J, Chan A K, Helms C, et al. Increasing sympathetic nerve terminal-dependent plasma extravasation correlates with decreased arthritic joint injury in rats. Neuroscience 1991; 40: 185-9.

25 Bernstock G. The changing face of autonomic neurotransmission. Acta Physiol Scand 1986; 126: 667-91.

26 Lundberg J M, Franco-Cereceda A, Hemsen A, Lacroix J S Pernow J. Pharmacology of noradrenaline and neuropeptide tyrosine (NPY)-mediated sympathetic cotransmission. .

27 Larson J, Ekblom A, Henriksson $\mathrm{K}$, et al. Concentration of substance $P$, neurokinin A, calcitonin gene-related peptide neuropeptide $\mathrm{Y}$ and vasoactive intestinal polypeptide in synovial fluid from knee joints in patients suffering from rheumatoid arthritis. Scand $\mathcal{Y}$ R heumatol 1991; 20: 326-35.

28 Michel M C. Receptors for neuropeptide Y: multiple subtypes and multiple second messengers. Trends Pharmacol Sci 1991; 12: 389-94.

29 Edvinsson L, Adamsson M, Jansen I. Neuropeptide $Y$ antagonistic properties of d-myo-inositol-trisphosphate in antine

30 Claxon A, Morris C, Blake D, et al. The anti-inflammatory effects of D-myo-inositol-1.2.6-trisphosphate (PP56) on animal models of inflammation. Agents Actions 1990; 29: animal
31 Kidd B L, Mapp P I, Blake D R, Gibson S J, Polak J M. Neurogenic influences in arthritis. Ann Rheum Dis $1990 ; 49$ Neurogenic

32 Holzer P. Local effector functions of capsaicin-sensitive nerve endings: involvement of tachykinins, calcitonin gene-related peptide and other neuropeptides. Neuroscience 1988; 24: 739-68.

33 Mapp P I, Kidd B L, Gibson S J, et al. Substance P. calcitonin-related peptide- and C-flanking peptide of neuropeptide Y-immunoreactive fibres are present in normal synovium but depleted in patients with rheumatoid arthritis. Neuroscience 1990; 37: 143-53.

34 Rees R G, Konttinen Y T, Hukkanen M, et al. The synovia innervation of normal and arthritic rats. $\mathrm{Br} \mathcal{F}$ Rheumatol 1989; 28 (suppl 2): 41 .

35 Hukkanen $M$, Konttinen Y T, Sergerberg M, et al. Neuropeptides and inflammatory cells in synovium; possible involvement of free radicals in neuropeptide degradation. $B$ f Rheumatol 1991; 30 (suppl 1): 5.

36 Blake $\mathrm{D}$, Merry $\mathrm{P}$, Unsworth J, et al. The inflamed human joint is an example of hypoxic-reperfusion injury. Lancet 1989; i: 289-93.

37 Stevens C R, Williams R B, Farrell A J, Blake D R. Hypoxia and inflammatory synovitis: observations and speculation and inflammatory synovitis: observat

38 Heathers G P, Evers A S, Corr P B. Enhanced inosito trisphosphate response to al-adrenergic stimulation in cardiac myosites exposed to hypoxia. $\mathcal{F}$ Clin Invest $1989 ; 83$; 1409-13.

39 Rhind V M, Bird H A, Wright V. A comparison of clinica assessments of disease activity in rheumatoid arthritis. $A n n$ Rheum Dis 1980; 39: 135-7.

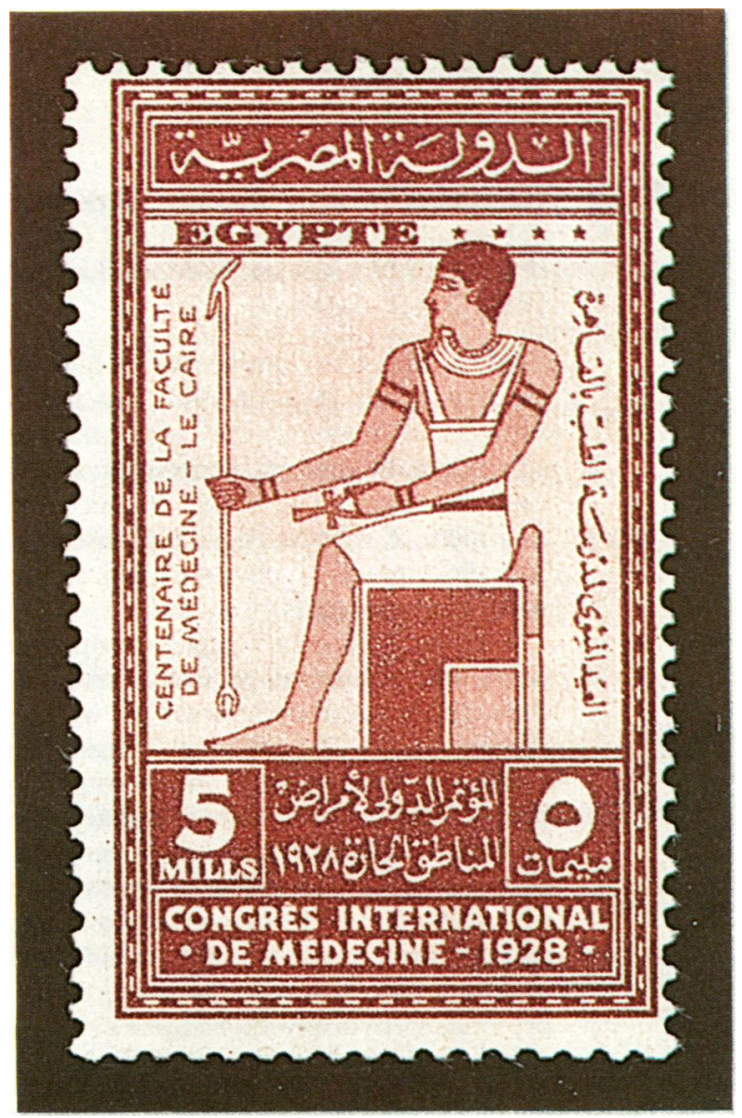

In 1928 Egypt honoured Imhotep (he who comes in peace). Imhotep was not only a grand vizier, architect, and personal physician of the Pharoahs and chief medical officer of the Kingdom, he was also deified by the Egyptians. He wrote that exercises are necessary 'to make the joints limber'. He also stated that working conditions of the slaves and peasants at the pyramids developed 'hardening of the limbs'.

YALE ANDELMAN 